\title{
APPlication OF OPTIMAL CONTROL ALGORITHM FOR DC MOTOR
}

\author{
Fedor Mitin \& Alexey Krivushov
}
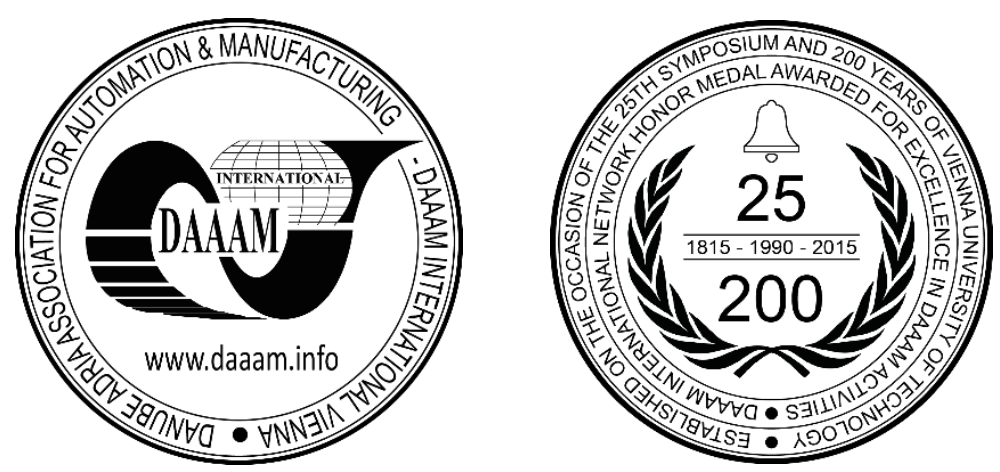

This Publication has to be referred as: Mitin, F[edor] \& Krivushov, A[lexey] (2018). Application of Optimal Control Algorithm for DC Motor, Proceedings of the 29th DAAAM International Symposium, pp.0762-0766, B. Katalinic (Ed.), Published by DAAAM International, ISBN 978-3-902734-20-4, ISSN 1726-9679, Vienna, Austria DOI: $10.2507 / 29$ th.daaam.proceedings.110

\begin{abstract}
This article considers the control of a DC motor as one of the most used in various mechanisms and machines, in particular in the space industry. With the modern development of computer technology, the use of regulators in which control algorithms are realized using the theory of optimal control becomes more relevant and justified. The effectiveness of the application of these algorithms has been studied by comparing them with the control based on PID control. The task of synthesis of control is solved at minimization of power consumption of the DC motor. The results show that the proposed optimal regulation makes it possible to achieve a better result among the methods considered.
\end{abstract}

Keywords: DC motor; optimal control; energy costs; PID controller; predictive model

\section{Introduction}

Electric motors are one of the most common electrical products. In view of its purpose (the transfer of electrical energy into mechanical energy), this type of engine has found its application in many fields of technology [1] and [2]. This is due to the wide range and smoothness of the motor speed control.

Despite the fact that the electric machine is well known and there are detailed mathematical models describing the processes that take place during its operation, control, in particular an electric motor with a direct current is an actual problem [3], [4], [5], [6], [7], [8], [9], [10], [11], [12] and [13]. The fact is that, depending on the specific task, the control algorithms will also differ.

Consider using a DC motor for the problem of tuning radio reflective network of a large-sized space-based reflector. Currently, research is being actively carried out to develop these structures [14], [15], [16], [17], [18] and [19].

Advantage of such structures is small dimensions during transportation, simultaneously with large volumes after deployment. This property leads to the fact that the radio reflective network can not be performed as a rigid structure, therefore, it is very actual to set the active surface [16] and [17]. After the deployment of the actual reflector, shape is not always the same as desired. This problem leads to the solution of several tasks: translation of reflective network from the actual position to the specified; the maintenance of the desired shape. Since the energy reserve is limited on the space-based reflector, the question of minimizing energy costs for the tasks is very important. 
Figure 1 shows the spoke 1, the two main cords of the rear 3 and frontal 2 nets and the cable 4 going between them. From the right end of the spoke 1 is divided into two parts to define the required shape of the reflective surface. In each cable 4 there is an actuator 5 for which a DC motor has been adopted in this task.

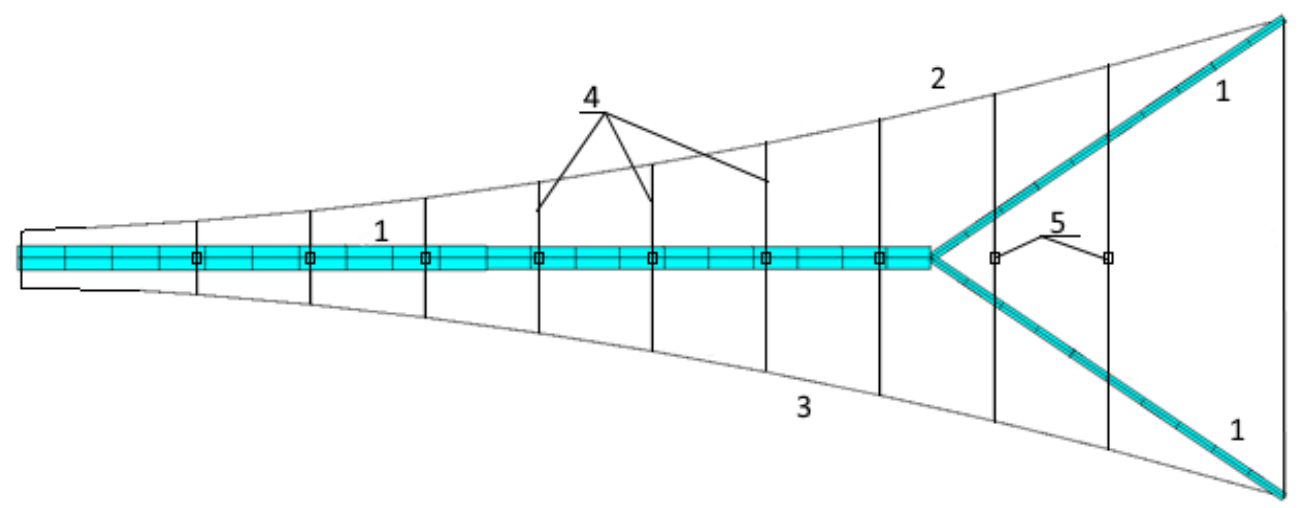

Fig. 1. Scheme of a spoke of a space-based reflector

It is necessary, by adjusting the length of the cable 4 with the help of actuators 5 , to set the shape of the reflective network defined by the front net 2 with minimizing energy costs. Let's assume that the task of controlling each actuator is separate. Before solving the control problem, it is necessary to determine the mathematical model of the object.

\section{Mathematical model of the DC motor}

Consider the mathematical model of the DC motor, given in [20]. The motor torque $M$ proportional to the armature current $I_{a}$, consumed by the motor from the power source, is calculated as:

$$
M=k_{m} \cdot I_{a}
$$

where $k_{m}$ is coefficient of proportionality, called motor torque constant. The total EMF (electromotive force) of the armature coils $E$ through the collector and brushes is applied to the outer terminals of the motor. In the driving mode of operation, this EMF is directed against the DC source voltage $U_{a}$, supplied to the armature from the power source. Therefore, the motor EMF is often called the back-EMF. It is directly proportional to the angular velocity of rotation of the motor shaft $\omega_{M}$

$$
E=k_{e} \cdot \omega_{M}
$$

where $k_{e}$ is coefficient of proportionality, called back EMF constant. The system of differential equations of the DC motor is compiled on the basis of the laws of physics. The first equation of a system of differential equations describing the motor characterizes the processes in the electrical part of the engine, and is written as [20]

$$
U_{a}-E=R_{a} \cdot I_{a}+L_{a} \cdot \frac{d I_{a}}{d t}
$$

where $R_{a}$ is armature resistance, $L_{a}$ is armature inductance. The term $R_{a} I_{a}$ in (3) characterizes the voltage drop on the active resistance, $L_{a} \frac{d I_{a}}{d t}$ represent the presence of the self-induced EMF that occurs in the winding when the armature current changes. Note that (3) does not take into account the voltage drop on the DC motor brushes, which depends nonlinearly on the armature current. The voltage drop on the motor brushes is relatively small compared to the voltage $U_{a}$.

The second differential equation of the system describing the DC motor characterizes the processes in the mechanical part of the motor

$$
J \cdot \frac{d \omega_{M}}{d t}=M-M_{f}
$$

Where $J$ is moment of inertia, $M_{f}$ is motor friction in general, acting relative to the axis of rotation of the motor shaft. A point above the corresponding variable will denote the time derivative. The system of equations describing the DC motor taking into account the assumptions made, will take the form [20] 


$$
\begin{aligned}
& \dot{I}_{a}=\frac{U_{a}-R_{a} \cdot I_{a}+k_{e} \cdot \omega_{M}}{L_{a}}, \\
& \dot{\omega}_{M}=\frac{k_{m} \cdot I_{a}-M_{f}}{J}, \\
& \dot{\varphi}_{M}=\omega_{M},
\end{aligned}
$$

where $\varphi_{M}$ is angle of rotation of the motor shaft. The control task is to bring the DC motor shaft from the initial position $\varphi_{M_{0}}=0$ degree, $\omega_{M_{0}}=0$ degree/second, $I_{a_{0}}=0 \mathrm{~A}$ to the specified final state $\varphi_{M_{f}}=180$ degree, $\omega_{M_{f}}=0$ degree/second, $I_{a_{f}}=0 \mathrm{~A}$ with a control limit, for which an DC source voltage is accepted, $U_{a}= \pm 6 \mathrm{~V}$. This rotation angle $\varphi_{M}$ will ensure the change of the length of the cable.

\section{Modeling}

One of the important problems in space control is the problem of energy efficiency, as the energy supply on the reflector is limited and it is necessary to perform the task, minimizing energy costs. To select the control, we will compare the use of different PID controller structure and the optimal controller.

In the simulation to determine the parameters of a DC motor, we take as the object of study the motor CH1, which is an analogue of the motor mabuchi FA-130. When modeling the system (5)-(7) with the use of different PID controller structures, it was possible to achieve the necessary parameters of system regulation with the use of all three components of the PID controller (figure 2). In this case, the measurement was available angle $\varphi_{M}$. The transient time was $\mathrm{t} \approx 0,75$ seconds. Adjustment of the regulator coefficients is carried out by tuning in the PID Controller block in Simulink.

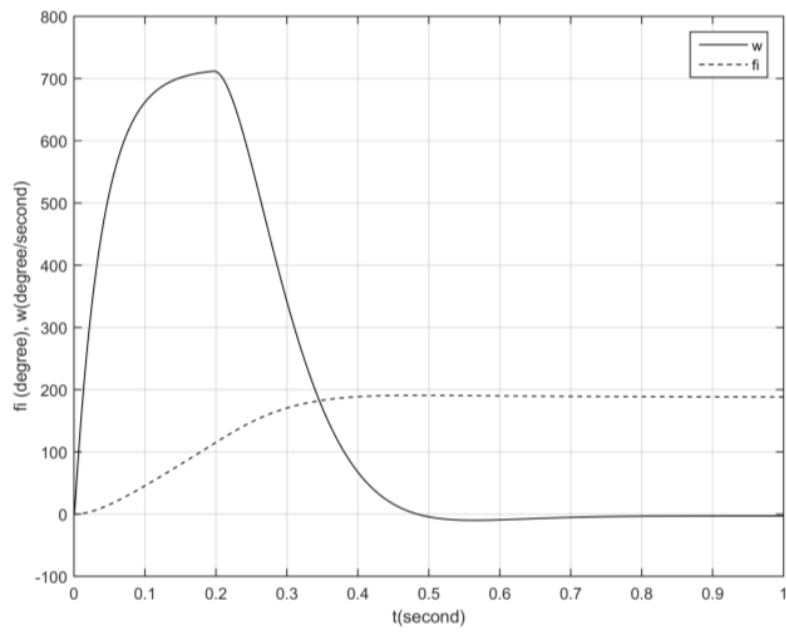

a)

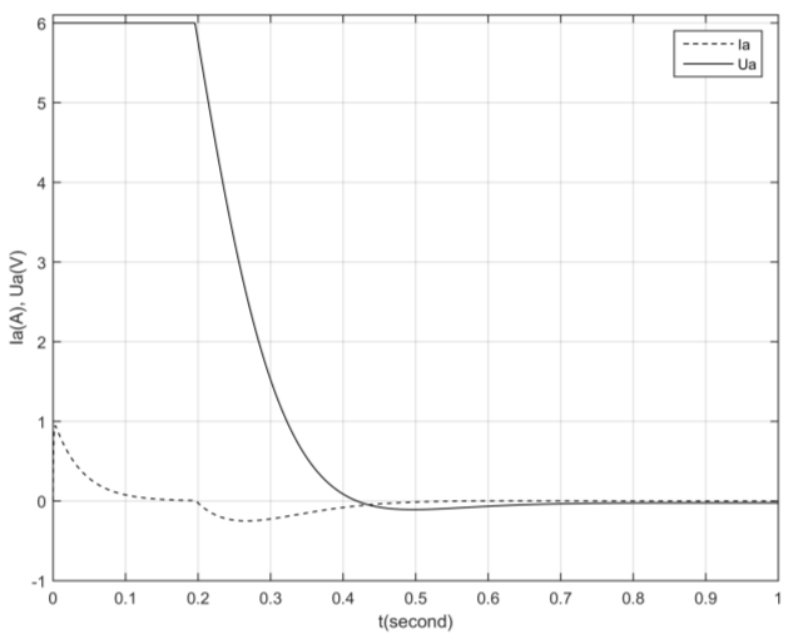

b)

Fig. 2. Transient processes with PID controller: a) the graphs of $\varphi_{M}(t)$ and $\omega_{M}(t)$; b) the graphs of $I_{a}(t)$ and $U_{a}(t)$

Similarly, the problem of controlling a DC motor using an optimal regulator is solved [21] and [22]. When optimizing the transfer of the system from one position to another with a fixed initial and final state, we choose the criterion of Bolza with the integro-terminal criterion:

$$
I=V_{f}\left(I_{a}, \omega_{M}, \varphi_{M}, t_{f}\right)+\int_{t_{0}}^{t_{f}} f_{0}\left(U_{a}, t\right) d t
$$

Assuming that $\quad V_{f}=0,5 \rho_{1}\left[I_{a}\left(t_{f}\right)-I_{a_{f}}\right]+0,5 \rho_{2}\left[\omega_{M}\left(t_{f}\right)-\omega_{M_{f}}\right]+0,5 \rho_{3}\left[\varphi_{M}\left(t_{f}\right)-\varphi_{M_{f}}\right], \quad f_{0}=0,5\left(\frac{U_{a}}{Z}\right)^{2}$, where $t_{0}$ is start time, $t_{f}$ is final time, $Z$ is the impedance of the armature winding. Since the task of minimizing energy costs was set, the expression for the consumed DC source voltage $U_{a}$ was taken as the function $f_{0}$ for the entire modeling interval. The Hamiltonian of the system (5)-(7) has the form

$$
H=P_{\varphi_{M}} \omega_{M}+P_{\omega_{M}} \frac{k_{m} \cdot I_{a}-M_{\text {external }}}{J}+P_{I_{a}} \frac{U_{a}-R_{a} \cdot I_{a}+k_{e} \cdot \omega_{M}}{L_{a}}+0,5\left(\frac{U_{a}}{Z}\right)^{2} .
$$

The equations for conjugate variables are obtained by taking partial derivatives of equation (9) with a negative sign:

$$
\dot{P}_{I_{a}}=-\frac{\partial H}{\partial I_{a}}=-P_{\omega_{M}} \frac{k_{m}}{J}+P_{I_{a}} \frac{R_{a}}{L_{a}}
$$




$$
\begin{aligned}
& \dot{P}_{\omega_{M}}=-\frac{\partial H}{\partial \omega_{M}}=-P_{\varphi_{M}}-P_{I_{a}} \frac{k_{e}}{L_{a}}, \\
& \dot{P}_{\varphi_{M}}=-\frac{\partial H}{\partial \varphi_{M}}=0 .
\end{aligned}
$$

The control is found from condition $\frac{\partial H}{\partial U_{a}}=0$ taking into account the limitation on the amount of control

$$
U_{a}=\left[\begin{array}{c}
6, \text { when } U_{a}(t) \geq 6 \\
-P_{I_{a}} \frac{z}{L_{a}}, \text { when }-6<U_{a}(t)<6 . \\
-6, \text { when } U_{a}(t) \leq-6
\end{array}\right.
$$

The problem of optimal control is proposed to be solved using an algorithm with a predictive model [21] and [22]. The control algorithm with the predictive model uses a sequence of control variables to optimize the future behavior of the control object. Optimal control is determined by predicting the free movement of a controlled object with a fixed control at time intervals. The output signal of the object is predicted with the help of a pre-constructed mathematical model of this process, which is the most important element of the system, since the control characteristics are directly dependent on it. The algorithm of the predictive model is described in detail in [22]. The simulation results are shown in figure 3 .

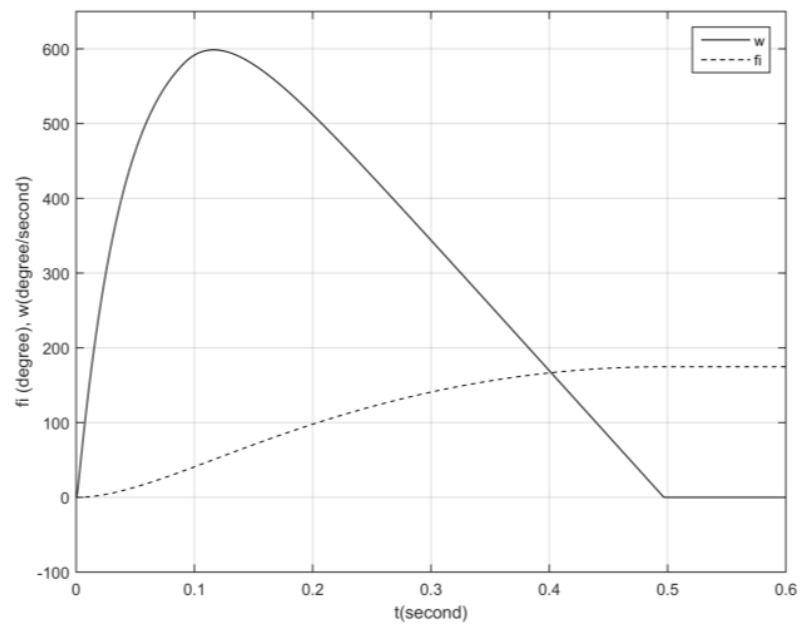

a)

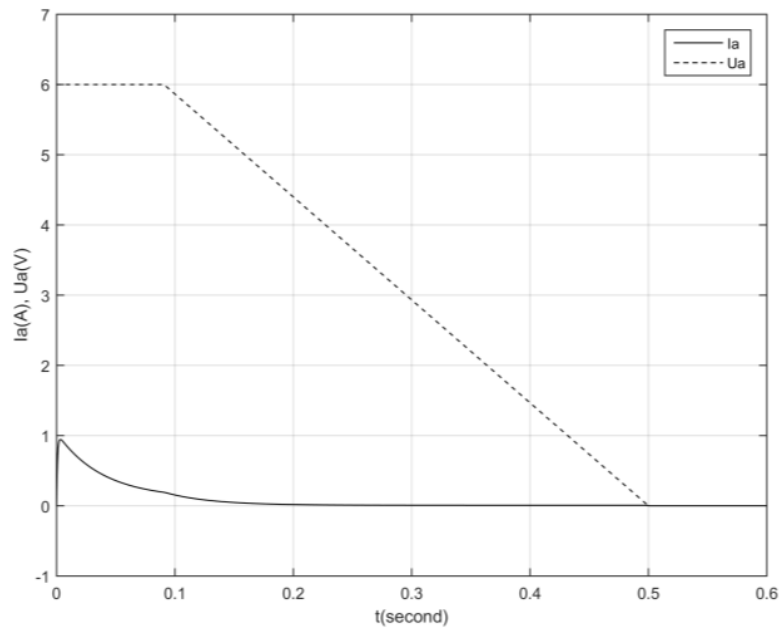

b)

Fig. 3. Transient processes with optimal control: a) the graphs of $\varphi_{M}(t)$ and $\omega_{M}(t) ;$ b) the graphs of $I_{a}(t)$ and $U_{a}(t)$

From the received characteristics it is visible, that the found control allows to reach final values on a angle, angular velocity, and also to armature current DC motor. There was no oscillatory process in the system. The transient time was $\mathrm{t} \approx 0,5$ seconds. At the same time, it was possible to reduce energy costs for a given control problem, as can be seen from comparing the graphs $I_{a}(t)$ and $U_{a}(t)$ in figures $2 \mathrm{~b}$ ) and $3 \mathrm{~b}$ ). Comparison of simulation results for different initial and final values for the PID controller and the optimal controller showed the advantage of using the optimal control algorithm.

\section{Conclusion}

The use of an optimal controller allows to reduce the time of the transition process in comparison with the PID controller, as well as to reduce energy costs. Thus, using the algorithm of the optimum control to customize the shape of space-based reflector due to regulation of a DC motor will allow you to optimize this process and, as a consequence, to maintain the desired shape network with the required accuracy.

It should be noted that the use of PID controller leads to the task of synthesis of control, that is, finding the law of control as a function of the current state of the object. Application of optimal control based on the algorithm with predictive model allows to solve the problem of both synthesis and control programming. That is, finding the control program, which is a dependence of the control action on time. This solution will further minimize energy costs. The results of this research can be used to calculate the energy costs, the choice of the actuator and the power plant on a space-based reflector. In the future, it is proposed to investigate the use of optimal control algorithms for a refined mathematical model of a DC motor. Including a model of the gearbox and a device that converts the angle of rotation of the motor shaft in changing the length of the cable. It is also planned to consider the problem of simultaneous control of multiple actuators for setting and maintaining a predetermined shape of space-based reflector. 


\section{Acknowledgments}

The work was carried out within the framework of the Federal target program "Research and development in priority areas of development of the scientific and technological complex of Russia for 2014-2020", the agreement on the grant № 4.574.21.0165 from September 26, 2017, the identification number of the project RFMEFI57417X0165: "Development of a wireless control system for the form of large-size transformable ground and space structures with the use of precision drives."

\section{References}

[1] Voldek, A. I. (1978). Electric machines. Textbook for high school students. tech. institutions. - 3rd ed., Energia, Leningrad

[2] Kundur, P. (1994). Power system stability and control. Mc. Graw-Holl, Inc, New York

[3] Kiseleva, O.A.; Vinokurov, S.A. \& Popova, T.V. (2017). Discrete equivalent to ideal vector control of the contactless engine of the direct current, Modeling, Optimization and Information Technology, Vol. 16, No 1, 2017, pp. 1-16.

[4] Gridin, V.M. (2017). Contactless torque DC motors with discrete and discrete-analog control with respect to rotor position, Electrical Technology Russia, Vol. 4, 2017, pp. 50-55.

[5] Gulyaev, I.V.; Volkov, A.V.; Ionova, E.I.; Popov, A.A. \& Bobrov, M.A. (2015). Comparative review of PMSM and BLDCM based on direct control method, Scientific and Technical Volga region Bulletin, Vol. 6, 2015, pp. 123-128.

[6] Renruk, V. (2014). Control of the DC motor, Components \& Technologies, Vol. 159, No 10, pp. 110-114.

[7] Bobikov, A.I. \& Surkov, I.I. (2015). Neural network speed control of DC motor, Vestnik of Ryazan State Radio Engineering University, Vol. 52, 2015, pp. 105-112.

[8] Nguyen, M. H. (2016). Optimal control DC motor with accounting elastic ties, Izvestiya of Tula state University. Technical science, Vol. 7-2, 2016, pp. 139-144.

[9] Shamseldin, M.A.; Ghany, M.A.A. \& Ghany, A.M.A. (2018). Performance study of enhanced non-linear PID control applied on brushless DC motor, International Journal of Power Electronics and Drive Systems, Vol. 9, No 2, 2018, pp. 536-545.

[10] Guzey, H.M.; Dumlu, A.; Guzey, N. \& Alpay, A. (2018). Optimal synchronizing speed control of multiple DC motors, Proceedings of the 4th International Conference on Optimization and Applications, ICOA, April 26-27 2018, Mohammedia, Morocco, pp. 1-5

[11] Pongfai, J. \& Assawinchaichote, W. (2017). Optimal PID parametric auto-Adjustment for BLDC motor control systems based on artificial intelligence, 2017 International Electrical Engineering Congress, iEECON, 8-10 March 2017, Pattaya, Thailand, pp. 8075892, DOI: 10.1109/IEECON.2017.8075892

[12] Song, Y.; Wang, Z.; Ding, D. \& Wei, G. (2016). Robust model predictive control under redundant channel transmission with applications in networked DC motor systems, International Journal of Robust and Nonlinear Control, Vol. 26, No 18, 2016, pp. 3937-3957.

[13] Livinti. P. \& Ghandour, M. (2014). Pwm Control of a Dc Motor Used to Drive a Conveyor Belt // Proceedings of 25th DAAAM International Symposium on Intelligent Manufacturing and Automation, DAAAM 2014, 26-28 November 2014, Vienna, Austria, pp. 299 - 304.

[14] Melnikov, V.M.; Matushenko, I.N.; Chernova, N.A. \& Harlov, B.N. (2014). The problems of creating large-size structures in space, Electronic journal «Trudy MAI», Vol. 78, 2014, pp. 1-21.

[15] Zhengrong, C.; Zongquan, D.; Xiaozhi, Q. \& Bing, L. (2014). Modeling and analysis of a large deployable antenna structure, Acta Astronautica, Vol. 131, 2014, pp 51-60.

[16] Yiqun, Z.; Wenrui, R.; Guigeng, Y. \& Na, L. (2016). Deployment analysis considering the cable-net tension effect for deployable antennas, Aerospace Science and Technology, Vol. 48, 2016, pp 193-202.

[17] Yiqun, Z.; Na, L.; Guigeng, Y. \& Wenrui, R. (2017). Dynamic analysis of the deployment for mesh reflector deployable antennas with the cable-net structure, Acta Astronautica, Vol. 131, 2017, pp 182-189.

[18] Kabanov, S.A.; Krivushov, A.I. \& Mitin, F.V. (2017). Modeling of joint deployment of units of the large-sized transformable reflector of space basing, SPIIRAS Proceedings, Vol.54, No 5, 2017, pp. 130-151.

[19] Mitin, F. \& Krivushov, A. (2017). Control deployment of mobile units of large-sized spacecraft, Proceedings of the 28th DAAAM International Symposium, pp. 0773-0779, B. Katalinic (Ed.), Published by DAAAM International, ISBN 978-3-902734-11-2, ISSN 1726-9679, Vienna, Austria DOI: 10.2507/28th.daaam.proceedings 109

[20] Petrov, U.P. (1971). Optimum control of the electric drive taking into account the limitations on heating, Energy, Leningrad.

[21] Handbook on the theory of automatic control, ed. Krasovsky, A. A. (1987). Nauka, Moscow.

[22] Kabanov, S.A. (1997). Control systems on predictive models, Publishing house of St. Petersburg State University, St. Petersburg. 